\title{
Entertainment-Education, American Style: Informing and Studying Hollywood's Portrayals of Social Issues
}

\author{
Erica L. Rosenthal and Kate Langrall Folb
}

It has become something of a cliché to say that entertainment has the power to influence hearts and minds, engage audiences on a massive scale, and inspire them to create lasting culture change. Decades of research have shown that because of the bonds we form with beloved characters, the emotions evoked by visual narratives, and our immersion into serial story worlds, entertainment can overcome the resistance we experience to more overt persuasive messages (Moyer-Gusé, 2008). As a result, entertainment is an attractive medium for communication campaigns that seek to reach mass audiences. Entertainment-education (EE), the intentional embedding of social or health messages in entertainment content, has been practiced since the late 1960s using television and radio, largely in the developing world (Singhal \& Rogers, 2002). Due to the nature of the American entertainment industry-profit-driven and relatively impermeable to outside influences, particularly from the government- the EE tradition was somewhat slower to emerge in the US.

E. L. Rosenthal $(\bowtie) \bullet$ K. L. Folb

The Norman Lear Center, USC Annenberg School for Communication and Journalism, Los Angeles, CA, USA

e-mail: erosenth@usc.edu; langrall@usc.edu

(C) The Author(s) 2021

L. B. Frank, P. Falzone (eds.), Entertainment-Education Behind the Scenes, https://doi.org/10.1007/978-3-030-63614-2_15 
One of the earliest entrants into the new American EE space was the University of Southern California's Norman Lear Center and its Hollywood, Health \& Society program (HH\&S). The Lear Center was founded in 2000 with a generous gift from Norman Lear-a trailblazer in the creation of TV programs with a social conscience-with the mission of both studying and shaping the impact of entertainment on society. We study entertainment through a program of research on the content of entertainment narratives, the characteristics of the audiences who consume them, and their impact on knowledge, attitudes, norms, and behavior. In addition, we shape entertainment narratives impact through a collaborative relationship HH\&S has developed and cultivated with the Hollywood creative community over the course of twenty years.

In this chapter, we tell the story of the emergence and evolution of a uniquely American form of EE. We discuss how the HH\&S approach differs from both traditional EE as practiced in the developing world and the strategies of advocacy groups in the US. We share several case studies from our outreach to the creative community and research on the content and impact of entertainment narratives. These stories are shared from the perspective of Kate Langrall Folb, an early pioneer in American EE and the director of HH\&S since 2012, and Erica Rosenthal, a communication researcher who led HH\&S research from 2011 to 2019 and currently oversees the broader Lear Center research portfolio. Finally, we conclude with a discussion of lessons learned and best practices.

\section{Hollywood, Health \& Society}

\section{The Emergence of $E E$ in the US}

In the late 1990s, the "Entertainment Media and Public Health" program at the Kaiser Family Foundation was the only true EE effort in the US. The Foundation partnered with MTV and BET to co-create public health TV specials and PSA campaigns based on HIV and reproductive health research. Around the same time, scores of advocacy groups arrived in Hollywood, hoping to influence TV and film depictions. Preventing addiction, reducing gun violence, smoking cessation, gender equality, securing rights for people with disabilities, and the LGBTQ community: these were just a few of the topics on which these advocates lobbied TV showrunners and movie screenwriters. For some content creators, the pressure was overwhelming. In search of accuracy without an agenda, 
writers began contacting the Centers for Disease Control \& Prevention (CDC) and other government agencies for help with their scripts. In 1998, the CDC established a small unit within its Office of the Director to act as liaison for Hollywood inquiries and to collaborate on academic studies of entertainment's impact on audiences.

However, the volume of inquiries led the CDC in 2000 to put out a request for proposals for a cooperative agreement between the agency and a non-government entity to handle the requests and act as a liaison between the creative community and the CDC. The contract was won by the newly established Norman Lear Center at the USC Annenberg School for Communication and Journalism in Los Angeles, the capital of the US entertainment industry. With this five-year award, the Lear Center launched the $H H \& S$ project. Its dual purposes were to serve as a "onestop shop" to connect writers seeking health information for their scripts with experts at CDC and elsewhere, and to conduct research on the effects of entertainment on audiences.

\section{The HHers Approach}

As defined by Singhal and Rogers (2002), EE is the process of purposefully designing and implementing a media message to both entertain and educate, in order to increase audience members' knowledge about an educational issue, create favorable attitudes, shift social norms, and change overt behavior. In this sense, HH\&S is not a traditional EE program. Whereas EE is designed to educate from the outset, HH\&S works with existing TV programs to inform and inspire accurate portrayals of health, safety, and security. Instead of developing a new show and hoping to attract an audience, HH\&S goes where the audiences already are-watching the most popular shows along with millions of other viewers-and offers to help its creators ensure accuracy and integrate additional, relevant information into their scripts. We don't press writers to take a particular point of view; we only advocate for the truth, the science, and the data.

HH\&S offers a variety of services to writers, producers, showrunners, network and studio executives, actors, and even art departments. Our methods include a response team that fields calls and emails on demand from writers - connecting them with information and experts from around the country, tip sheets covering an assortment of topics, a quarterly newsletter, expert panel discussions, screenings and talk-backs, "On Location" field trips designed to give writers an intimate look inside a subject area, 
and social media support for episodes and storylines. We sponsor the annual Sentinel Awards which recognize exemplary achievements in TV storylines that inform, educate, and motivate viewers to make choices for healthier and safer lives. The awards serve as an incentive, as well as an opportunity to promote the winning shows, their stars, and the writerswho are rarely celebrated in Hollywood. HH\&S is considered by the industry to be a valuable support organization, officially partnered with the Writers Guild of America, West (WGAW) and East (WGAE), the Television Academy and the Producers Guild. Since its inception, HH\&S has held over 4000 consultations with TV writers from hundreds of shows spanning dozens of broadcast networks, cable, and streaming channels.

Around 2011, HH\&S began expanding its reach beyond topics traditionally classified as health. The first new focus was climate change, a growing concern at CDC as well as other funders. Later, through a grant from the California Endowment, HH\&S presented the realities of the Affordable Care Act, which had just been passed into law and would start in the coming years. This included dispelling myths and misinformation that had permeated the national conversation leading up to its passing, as well as helping writers understand the status of immigrants in relation to health coverage. In 2015, through a grant from N Square, HH\&S began a campaign to inform and inspire storylines around nuclear weapons proliferation, nuclear policy, and national security. Today, HH\&S also focuses on the social determinants of health including racial equity, homelessness, and access to care.

\section{Challenges of Working with US Entertainment Industry}

The US entertainment industry is unlike that of other countries-particularly the developing world. Traditionally, EE programs have been supported through collaborative efforts between US government agencies such as CDC, United Nations agencies such as UNICEF, and other philanthropic organizations, and often have the support of local government broadcasting agencies (Singhal, Cody, Rogers, \& Sabido, 2004). The US television entertainment business is a profit-based enterprise, largely independent, where the financial bottom-line is the guiding factor in decisionmaking. Entertainment value-what will garner the most eyeballs-is paramount. Writers - as well as networks - want viewers, and will do what it takes to get them and keep them. Only then will they consider a public health message. However, erroneous depictions can cause backlash, 
previously in the form of letter writing campaigns and more recently through social media. Thus, it behooves writers to strive for accuracy if only to keep their viewers engaged.

\section{Research}

Since its beginnings, HH\&S has collaborated with other health communication scholars to study the impact of the fictional TV storylines on which it consulted. This research has addressed a variety of topics from HIV and other STIs (Kennedy, O'Leary, Beck, Pollard, \& Simpson, 2004) to cancer (Hether, Huang, Beck, Murphy, \& Valente, 2008) and more. Drawing upon the theoretical frameworks of Moyer-Gusé, Slater and Rouner (2002), and others, this research has incorporated mechanisms of narrative influence such as narrative transportation, character identification, and emotional responses to entertainment (Murphy, Frank, Moran, \& Patnoe-Woodley, 2011). We have studied the impact of shows explicitly designed to educate and promote behavior change, such as East Los High (Walter, Murphy, \& Rosenthal, 2018), as well as those for which entertaining the audience is of paramount importance, such as the 200890210 reboot (Rosenthal, Buffington, \& Cole, 2018). In addition to impact research, since 2003 we have conducted content analysis of representations of health and other public interest issues on TV (Murphy, Wilkin, Cody, \& Huang, 2008). In 2013, with the establishment of the Media Impact Project (MIP), the Lear Center expanded its research enterprise beyond HH\&S-informed TV storylines. MIP partners with media organizations, advocacy groups, and philanthropic partners to study the ways in which a variety of media-including documentary and feature films (Blakley, Huang, Huh, Nahm, \& Shin, 2016; Blakley, Huang, Nahm, \& Shin, 2016), journalism (Karlin, Chapman, \& Saucier, 2018), and virtual reality (Karlin, Kim, Kelly, Blakley, Brenner, \& Riley, 2018)—serve the social good.

\section{Case Studies}

Below, we share case studies describing our outreach to the entertainment industry and research on four issues of public interest. For climate change and nuclear threats, we describe the outreach process, but highlight relevant research findings. Case studies on transgender inclusion and immigration focus primarily on research, including how we partner with other 
organizations to study the impact of their "narrative strategy" work. For each topic, we highlight specific challenges and considerations.

\section{Climate Change}

HH\&S began its Climate Change Initiative in 2011 to enable TV writers, producers, and other entertainment industry professionals to accurately portray the ways that climate change impacts human health in TV, film, and streaming storylines. The effort faced several challenges, the first of which was the entertainment industry's lack of understanding of climate change in general, and beyond that, how to tell stories that would illustrate this perceived slow-moving phenomenon. At the home of Lyn and Norman Lear, we held a series of salons with high-level entertainment industry decision-makers and notable climate change advocates, scientists, and NGOs (e.g. Bill McKibbon of 350.org, Jim Hansen of Columbia University, and UN Secretary-General Ban Ki-moon). We also held industry screenings and talk-backs of relevant films including Racing Extinction by Louis Psyhoyos, panel discussions with experts like Anthony Leiserowitz of the Yale Program on Climate Change Communication and retired Brigadier General W. Christopher King, and “On Location” trips taking writers to NASA-JPL or Santa Cruz Island to learn about climate research and the people behind it. The purpose of all these activities was to inspire TV storytellers, filmmakers, event producers, and others to incorporate climate change into their work however and whenever possible.

Another challenge was resistance from the TV networks to air storylines or even brief mentions of climate change. We were never told the reason for their hesitancy, but we speculate that between concern for the range of political perspectives that make up their audiences and fear of backlash from advertisers, networks were reluctant to feature anything related to the issue. Nevertheless, certain showrunners and writers with enough clout were able to get a few storylines on the air, though they were sometimes watered down.

For example, through HH\&S outreach and consultation, the CBS Madam Secretary episode, "Face the Nation," included a minor storyline about extraction of the Amazonian oil supplies and their potential effect on the climate. As Secretary of State Elizabeth McCord (played by Téa Leoni) is having her blood drawn, an intern briefs her on the situation. The intern becomes queasy and struggles to get through her presentation, eventually running out of the room in distress. The scene is comical and 
seems to lessen the impact of the information presented. A subsequent scene shows Secretary McCord uncharacteristically shouting at the Chinese ambassador. Referencing the Amazon rainforest, she cries, "If we chop it all down, we pretty much guarantee the planet overheats, and our kids will live in a totally destabilized world!" After the outburst, she faints due to what is later determined to be PTSD, thus minimizing the point. HH\&S also encouraged a 2014 Doc McStuffins (Disney Jr.) episode "The Big Storm," which features the wise owl saying "I was reading about this: as the earth gets warmer and warmer, big storms get bigger and bigger." The line was contested by the network, but ultimately allowed.

While we never studied the impact of an HH\&S-informed climate change storyline, we examined the frequency and context of these issues on prime-time TV from 2012 through 2018 as part of our TV Monitoring Project. Unpublished data from this project suggest that climate change has been very infrequently discussed or even mentioned on prime-time broadcast TV. There have been numerous storylines involving severe weather such as hurricanes, blizzards, and wildfires, but rarely do these stories draw an explicit connection between the frequency and severity of extreme weather events and climate change. We did see evidence of what is termed "greening the set" in corporate social responsibility parlance: visual cues of environmental sustainability with little or no related dialogue. Homes may have solar panels installed. Trash cans are replaced with recycling bins. Characters carry reusable water bottles or shopping bags, and occasionally walk or take public transit.

As outreach efforts continued, though there was no measurable increase in the number of storylines, we anecdotally saw a greater emphasis placed on climate change in some shows. A notable trend has been the portrayal of climate scientists or environmentalist characters as villains or otherwise worthy of derision. For example, the Modern Family episode "Under Pressure" features Mitchell and Cam's neighbor, Asher (guest star Jesse Eisenberg), an extreme environmentalist. The episode opens as Asher comments that Mitchell's air conditioner is constantly running. When Mitchell responds "Oh, my partner runs a little hot," Asher sarcastically replies, "Not as hot as our planet." The episode revolves around Mitchell's quest to prove to Asher that he also cares about the planet. The substantive climate messages in this episode are undercut to some extent by the portrayal of Asher as pedantic and "holier-than-thou."

More recently, we have seen some substantial climate change storylines. In 2019, with the help of HH\&S, Madam Secretary aired "The New 
Normal," in which a massive typhoon dubbed Blessing is headed toward the US. NASA confirms that it will be the most powerful storm in history, but due to global warming it also represents a "new normal." Eventually, the storm changes course, moving instead toward the small island nation of Nairu. Secretary McCord must convince the island's president and all its people to evacuate permanently, while also hoping to develop a resiliency fund to help other countries devastated by this new normal. The president is reluctant to take the matter to Congress, not denying the existence of climate change, but worrying that a "no" vote would shut down the entire environmental agenda for years. This season 5 episode provided a sobering take on climate change and even pointed out how the government had ignored warnings of climate scientists in the past. Live and DVR ratings indicated that 8.2 million people watched (Wikipedia, n.d.-b).

\section{Nuclear Threats}

In 2015, HH\&S began an effort to inform and inspire TV storylines on the threat nuclear weapons and nuclear proliferation pose to the American public and the world (Fig. 15.2). We consulted with a number of shows including The Black List, NCIS: Los Angeles, MacGyver, Hawaii Five-O, Magnum P.I., and Madam Secretary. While most of these shows created episodes that touched on the issue, the writers at Madam Secretary were particularly passionate about exploring the topic. HH\&S brought a number of nuclear experts into the show's writers' room, including former US Secretary of Energy Ernest Moniz, to discuss the issues in detail.

The season 4 finale, "Night Watch," features President Dalton announcing a retaliatory nuclear strike on a nation that has launched missiles at the US. The strike is aborted with only seconds to spare after it is discovered to be a simulation gone awry. The Secretary of State squares off against the administration and Pentagon officials over long-standing and outdated nuclear launch policies and advocates to end the hair-trigger alert on land missiles. According to ratings data, viewership of this episode was 8.73 million including live and DVR viewing (Wikipedia, n.d.-a). HH\&S developed a comprehensive campaign that included real-time social media posts in concert with the show, CBS and the nuclear non-proliferation community causing Madam Secretary to trend for two hours on Twitter. The campaign also included a Reddit "Ask Me Anything" session with Secretary Moniz and executive producer David Grae with 6000 tuning in, 


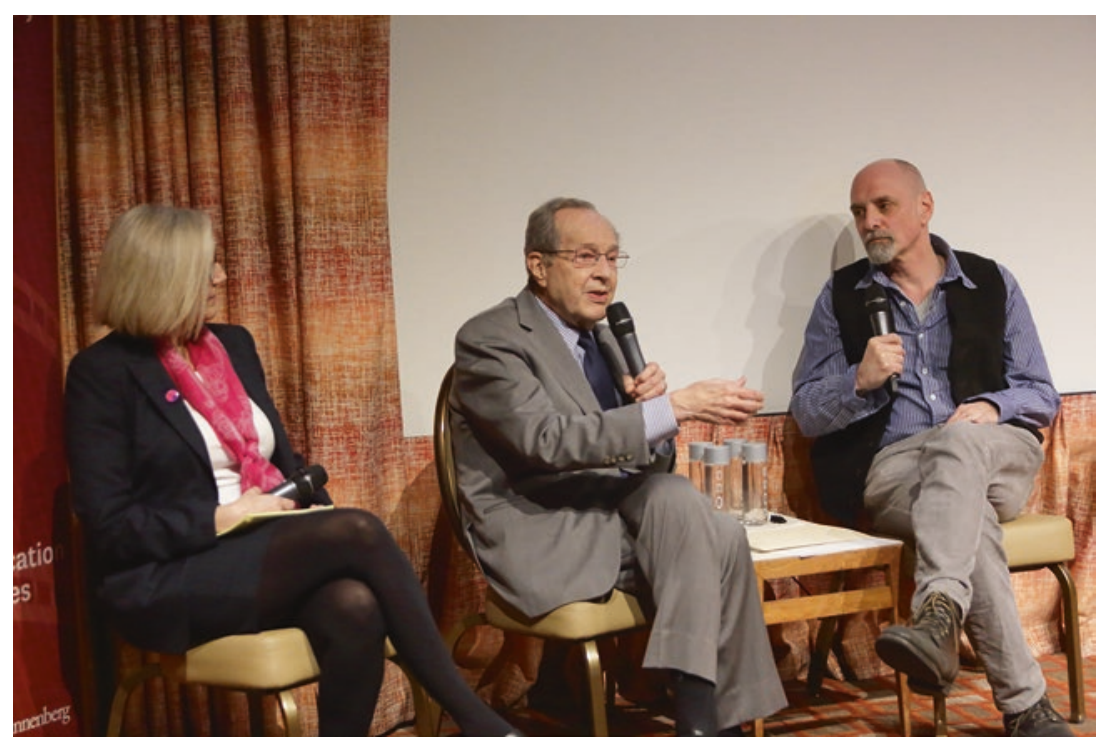

Fig. 15.1 HH\&S Director Folb (left) with former Sec. of Defense William Perry (center) and journalist and filmmaker Eric Schlosser (right) at the nuclear initiative kickoff event

and a screening party and panel discussion at the WGAW, co-hosted with the Ploughshares Fund, for more than 100 attendees from the entertainment industry.

To measure the impact of this storyline, we conducted a pretest/posttest survey of regular Madam Secretary viewers. After controlling for political party affiliation, exposure to nuclear issues through the news, and other demographic variables, we found an increase in knowledge about hair-trigger alert (Kim \& Rosenthal, 2020). Further, differences in ideology and core beliefs appear to have driven responses to the storyline; it had a greater impact on knowledge among the subgroup of more liberal, anti-war, and anti-nuclear viewers.

\section{Transgender Inclusion}

HH\&S has supported storylines on a variety of LGBTQ issues throughout our 20-year history. In fact, the impetus for the program originated 


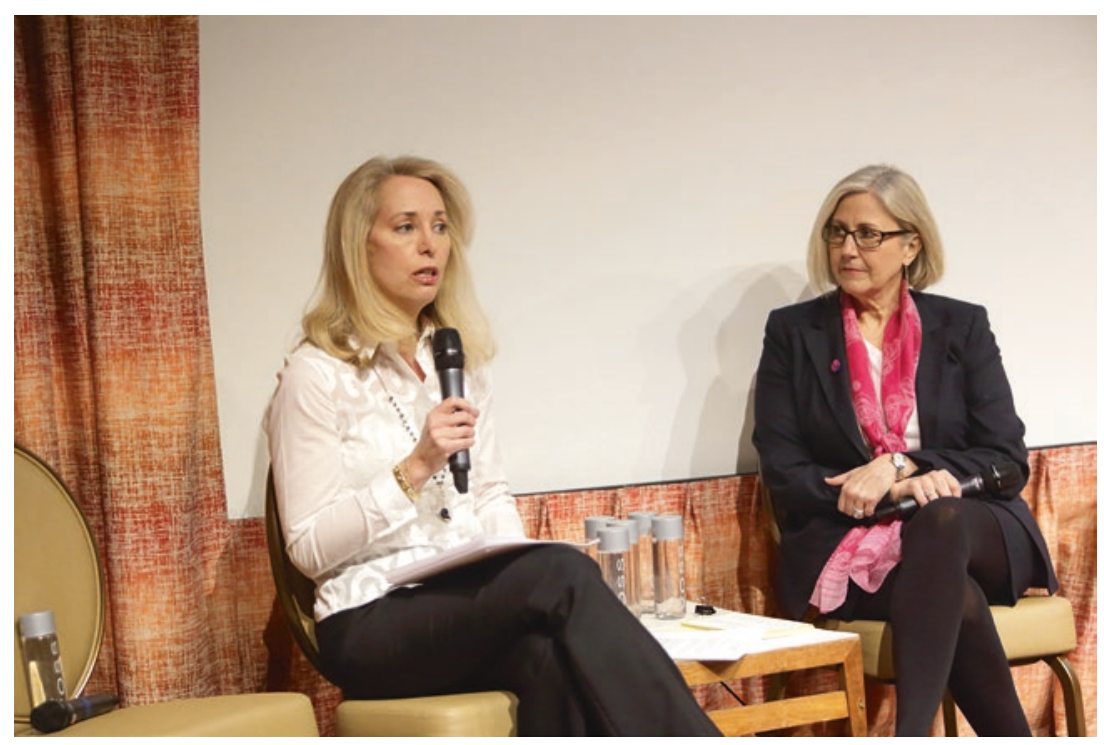

Fig. 15.2 Kate Folb, Director of HH\&S with former CIA agent Valerie Plame Wilson at the nuclear initiative kickoff event

from the CDC's HIV prevention effort in 1998. Since then, we have consulted on dozens of storylines beyond HIV that affect the LGBTQ community, including transgender health on Grey's Anatomy, How to Get Away with Murder, and others.

In June 2015, in the midst of what has been called the "transgender tipping point" (Steinmetz, 2014), the long-running USA Network series Royal Pains contacted HH\&S for consultation on a storyline about a transgender teen named Anna, who is experiencing health complications associated with her transition. HH\&S connected the show's writers with Dr. John Turco, an expert in transgender hormonal therapy. Rather than stick to a purely medical story, the writers chose to have lead character Dr. Hank Lawson model empathy and compassion toward Anna. Initially hesitant to let Anna continue hormonal treatment because of a clotting disorder that is exacerbated by estrogen, Hank ultimately realizes these risks must be balanced against the risks to Anna's mental health of being unable to align her physical appearance with her gender identity. Notably, Anna was played by transgender actor and youth activist Nicole Maines. 
This storyline provided a unique research opportunity for a number of reasons. First, while several shows at the time prominently featured transgender characters (e.g., Transparent, Orange is the New Black), these were predominantly streaming shows with fairly niche audiences. Royal Pains, on the other hand, was a soapy basic cable series about a disgraced former ER doctor, who works under the table as a "concierge doctor" in the Hamptons. It ran for nine seasons to no major critical acclaim, and had no particular history of addressing LGBTQ issues. Because this 11-minute storyline was a secondary storyline in the episode, it was not teased ahead of time. Thus, we had no reason to expect the episode would draw an audience already supportive of transgender inclusion. Second, the episode aired in the context of an extremely high-profile real-life transition-that of former Olympian and reality TV star Caitlyn Jenner. Nearly 17 million people watched Jenner announce her transition on 20/20 on April 24, 2015, Vanity Fair released its "Call Me Caitlyn" cover on June 1, the Royal Pains episode aired on June 23, and the E! reality series I am Cait premiered on July 26 . The timing of the episode provided an opportunity to measure the impact of exposure to this storyline alongside exposure to the Jenner transition in the news and other shows with transgender characters.

In collaboration with USC Annenberg faculty and graduate students, we conducted a study of the impact of this brief storyline on regular viewers of Royal Pains (Gillig, Rosenthal, Murphy, \& Folb, 2018). By virtue of HH\&S' proximity to TV writers, we often have advanced knowledge of upcoming storylines. We were able to obtain the script ahead of time, but did not have sufficient notice to develop and implement a pretest survey. USA Network did, however, work with the research team to distribute the survey link via the show's social media platforms following the episode. To maximize comparability, all participants were required to be regular viewers of Royal Pains, defined as having seen at least one of the three most recent episodes.

We found that Royal Pains viewers who saw the 11-minute storyline about Anna's transition had more supportive attitudes toward both transgender people and related policies. Exposure to transgender stories in the news, including the ubiquitous Caitlyn Jenner story, had no such impact on attitudes. As expected, political ideology was a primary driver of responses to the storyline. Liberal viewers were more likely to feel hope or identify with Anna, whereas conservative viewers were more likely to react with disgust. Further, while news stories were not able to overcome 
ideological bias, entertainment depictions were. The more shows with transgender characters viewers saw, the more positive their attitudes toward transgender people and policies. This impact was particularly pronounced among ideologically conservative viewers who saw two or more shows with transgender characters.

The study was published online in August 2017, a time when transgender policy issues were very much in the news. President Trump had just pronounced that the US military would no longer allow transgender individuals to serve. To maximize the reach of this research beyond academia, we published a piece in The Conversation (Rosenthal \& Gillig, 2017), a media outlet for academic researchers to translate their findings for lay audiences. The article was picked up by a number of outlets including The San Francisco Chronicle, The Washington Post, and Newsweek, drawing both positive attention and controversy.

\section{Immigration}

Through the Media Impact Project (MIP), the Lear Center conducts research on entertainment storylines that HH\&S did not help to inform, and partners with advocacy groups to study the impact of their entertainment outreach. In 2017, we were approached by Define American, an organization focused on using "the power of storytelling to transcend politics and shift the conversation about immigrants, identity, and citizenship in a changing America" (Define American, n.d.; see Borum Chattoo's chapter in this volume for more about Define American). The Opportunity Agenda had just published its own report on immigrant representation on TV (2017), and Define American was interested in building upon this study by tracking the stories being told about immigrants and immigration longitudinally. In partnership with Define American, we have been studying this content since the 2017-2018 television season.

In 2017-2018, we analyzed the demographic, socioeconomic, and social representations of immigrant characters depicted, as well as the context and use of terms relating to immigration (Blakley, Rogers, Saucier, Watson-Currie, \& Trotta-Valenti, 2018). For the 2018-2019 season, we developed a more systematic sampling frame to include all known immigrant characters. We analyzed depictions of 129 unique immigrant characters across 97 episodes of 59 shows, examining both the nature of depictions of immigrants and the broader storylines in which these characters sometimes featured. The report "Change the Narrative, Change the 
World" (Rosenthal, Rogers, Peterson, Watson-Currie, \& Shin, 2020) compares the data against both the 2017-2018 findings and real-world immigration statistics. Relative to reality, we found that Asian Pacific Islander and senior immigrants (over the age of 65) were underrepresented, and Middle Eastern immigrants were over-represented. Only a small percentage of immigrant characters had an explicitly identified religion, but of these, nearly a third were Muslims, largely due to the role of religion in the Hulu series Ramy. Twenty-two percent of immigrant characters were associated with a crime, a substantial drop from the $34 \%$ of TV immigrant characters associated with a crime in 2017-2018, but still vastly over-represented relative to the real world. Finally, of those characters with an identified immigration status, $63 \%$ were undocumented immigrants or asylum seekers. This number is much higher than both 2017-2018 and reality.

For the 2018-2019 season, we also analyzed the impact of three key immigration storylines from Madam Secretary (CBS), Orange is the New Black (Netflix), and Superstore (NBC). The Madam Secretary storyline, which spanned two episodes, addresses family separation in an immigrant detention center near the border. On Orange, the immigration storyline focuses on an ICE detention center alongside the primary prison setting, and runs throughout the entire seventh season. The storyline also features a harrowing scene of deportation hearings involving young children unable to speak English and without legal counsel. Superstore is the only one of the three shows to feature a regular immigrant character, Mateo, an undocumented worker whose fellow employees shelter him from an ICE raid (see Borum Chattoo, 2021 for more information about this storyline, on which Define American consulted).

For all three shows, those who saw the immigration storyline had more inclusive attitudes toward immigrants and were more likely to take associated immigration-related actions than viewers of the relevant show who did not see the relevant storyline. Further, those who experienced negative emotions while watching had more inclusive attitudes toward immigrants and were more likely to take immigration-related actions. This was due in part to being transported (Green, 2021) into the story world . Among those who saw the Madam Secretary storyline, attitudes toward immigrants were more inclusive than those who did not, but only among viewers who were not very religious, and particularly for those living in rural settings. Additionally, for Madam Secretary viewers, those who experienced empathy had greater immigration knowledge and more inclusive 
attitudes, particularly among those whose entertainment choices were not primarily driven by a desire for pleasure or fun. Finally, viewers of the Superstore storyline who experienced parasocial interaction-a sense of friendship — with Mateo were more likely to support an increase in immigrants coming to the US, particularly among those who had little or no real-life contact with immigrants.

\section{Lessons Learned and Best Practices}

\section{Collaboration over Confrontation}

The US creative community is inimitably American in that it rejects being told what to do. Mandates by networks and studios can backfire and result in insincere depictions or satire that mocks the initiative and sends the opposite message. As such, HH\&S approaches its work with the entertainment industry from a place of collaboration, not confrontation. There are hundreds of advocacy groups watching Hollywood who make their voices heard in the event of inaccurate or biased programming. Viewed by the industry as an ally and a supportive resource, HH\&S is in a unique position to help writers "get it right" without blaming, shaming, or forcing the issue. Our desire to maintain a positive relationship with the entertainment industry means we are hesitant to take on work that aims to use research findings as a "stick" rather than a "carrot." The hands-off approach of providing accurate, proven scientific information allows writers to come to their own conclusions about what kinds of stories they choose to tell, and simultaneously addresses many of the advocates' concerns. It's a longer game, but the resulting stories are more authentic, nuanced, and compelling.

\section{Balancing Rigor and Feasibility}

The Lear Center has always strived to apply rigorous research methods and academic theory to the study of entertainment, often in real time. Over the past ten years, efforts to "change the narrative" around public interest issues have gained traction and transitioned away from being a primarily academic endeavor in the field of health communication. These practical efforts, sometimes described as social impact entertainment or narrative strategy (Borum Chattoo, 2021), have become a collaborative effort across the entertainment industry, the philanthropic sector, and 
activist and advocacy organizations. Many practitioners in this world shun the EE label, which may be perceived as too pedantic or inauthentic. Others may find the collaborative approach of HH\&S inadequate, preferring a more "disruptive" strategy to promote radical change in the entertainment industry.

With the founding of MIP in 2013, the Lear Center sought to be more responsive to the measurement needs of this burgeoning field. Whereas HH\&S research has traditionally been internally initiated and intended for publication in academic journals, MIP research is largely client-driven and intended for dissemination to the entertainment industry and other practitioners in highly digested and actionable reports. The primary objective of MIP research is delivering data-driven insights that content creators can apply toward the goal of telling inclusive and authentic stories that serve the greater good.

In both HH\&S and MIP research, we seek a balance between meeting client needs, often in terms of budget and timeline, and maintaining a high level of rigor. In many cases, this means prioritizing ecological validity (the realism and authenticity of the research context and tasks) over internal validity (maintaining strict control to allow for causal conclusions). Content creators typically want to know how their actual audience responds in a real-world viewing context. Thus, we usually conduct pretest/posttest surveys of regular viewers (or in some cases posttest only), rather than tightly controlled experimental research. Further, we rarely have the opportunity to conduct longitudinal research on the impact of entertainment narratives, due to the expense associated with participant follow-up and attrition.

Another major challenge in media impact research, particularly when studying natural audiences, is addressing selection bias. Those who choose to watch, for example, a documentary like Waiting for "Superman" may start out with much different attitudes and behavior than those who bypass this content. It is not appropriate to simply compare viewers against non-viewers, so we sometimes use propensity score methods (Blakley \& Nahm, 2018) to generate a matched comparison group. Each exposed participant is paired with a corresponding unexposed person who has an equal propensity or likelihood of seeking out the content, based on other factors that predict exposure. In this way, we are essentially able to compare "apples to apples." 


\section{Entertainment in the COVID and Post-COVID Eva}

The COVID-19 pandemic and widespread protests around racial injustice in policing following the murders of George Floyd, Breonna Taylor, and Ahmaud Arbery have pulled back the curtain on government failures and structural inequities in unprecedented ways. While none of these inequities are new, many Americans are grasping these effects for the first time, and public opinion is changing rapidly (Parker, Horowitz, \& Anderson, 2020). How will the entertainment industry respond to the tumultuous events of 2020?

In the short term, the pandemic presents a unique set of challenges, compounded by uncertainty around production protocols. In mid-March 2020 , virtually all TV and film production ground to a halt, with the exception of some talk shows, late-night comedy, and animation. Some shows were able to wrap their story arcs early while others simply stopped, hoping to complete the season in the coming months. Many writers' rooms, after a short break, resumed virtually, even without a definitive return to production date and $\mathrm{HH} \& \mathrm{~S}$ has continued to consult with them. At the start of the shutdown, HH\&S partnered with the WGAE and WGAW to host a series of weekly, online panels on a range of topics affected by the pandemic. At the time of this writing, HH\&S has hosted sixteen virtual panels, many of which featured up-to-date information on COVID-19 (such as the search for a vaccine) or its intersection with other health issues like mental health, addiction, and HIV. Others have explored the impact of racism on democracy, maternal health, and the criminal justice system. HH\&S strives to keep TV content creators up to date with important developments on COVID-19, but this is challenging due to rapidly changing information. Before the pandemic, the time between an episode's conception and its airing could be several months to a year. As a result of the production shutdown, delays are likely to be significantly longer, and some information may be outdated by the time it airs. However, some soap operas resumed production in June and July, and $\mathrm{HH} \& \mathrm{~S}$ continues to support them.

In a series of interviews conducted with support from the Bill \& Melinda Gates Foundation (Jauriqui, 2020), we asked entertainment industry leaders and subject matter experts how they anticipated the COVID-19 crisis would affect Hollywood in the long term. Some speculated that the pandemic, combined with the Black Lives Matter movement, would push entertainment to shine a light on the systemic issues 
being brought to the fore, with shifts toward greater diversity in storytelling and correction of historical inaccuracies, including around slavery and the founding of this nation. Several shows, including Grey's Anatomy, Station 19 (ABC), Doc McStuffins (Disney Junior), Kung Fu (The CW), Unbreakable Kimmy Schmidt (Netflix), This Is Us, and Law and Order: Organized Crime (NBC), have already decided to tackle COVID-19 in their storylines and have contacted HH\&S for help. Other experts predict we will see a rise in escapist stories, as audiences seek refuge from the reality of daily life. At a recent entertainment conference, a representative from Creative Artists Agency (CAA) said, "Don't bring us any dystopian, post-apocalyptic or pandemic-related projects. We're not even going to read them" (Anonymous, personal communication, July 14, 2020). Still others believed it was too early to know. "It's really hard to ask people how they're going to process the car accident when they're still in the midst of it" (Jauriqui, p. 17), said John David Coles, executive producer of NBC's New Amsterdam. At this time, only one thing seems certain; when future creators and cataloguers of culture look back on this era, they will speak of the world in pre- and post-2020 terms.

\section{REFERENCES}

Blakley, J., Huang, G., Huh, J., Nahm, S., \& Shin, H. (2016). Preaching to the choir? Measuring the impact of Waiting for "Superman". USC Annenberg Norman Lear Center. Retrieved from https://learcenter.org/wp-content/ uploads/2016/11/WaitingForSupermanReport.pdf

Blakley, J., Huang, G., Nahm, S., \& Shin, H. (2016). Changing appetites \& changing minds: Measuring the impact of Food, Inc. USC Annenberg Norman Lear Center. Retrieved from https://learcenter.org/wp-content/ uploads/2016/06/Food-Inc-Summary-Report.pdf

Blakley, J., \& Nahm, S. (2018). Accounting for taste: Using propensity score methods to evaluate the documentary film, Waiting for "Superman". In R. Rajan \& I. C. O'Neal (Eds.), Arts evaluation and assessment measuring impact in schools and communities (pp. 271-295). Palgrave Macmillan.

Blakley, J., Rogers, A. A., Saucier, C., Watson-Currie, E., \& Trotta-Valenti, L. (2018). Immigration nation: Exploring immigrant portrayals on television. A report to Define American. USC Annenberg Norman Lear Center. Retrieved from http://www.mediaimpactproject.org/uploads/5/1/2/7/5127770/ immigration_nation_report_final_l.pdf

Borum Chattoo, C. (2021). Entertainment-education as social justice activism in the United States: Narrative strategy in the participatory media era. In L. Frank 
\& P. Falzone (Eds.), Entertainment-education behind the scenes: Case studies for theory and practice. Palgrave Macmillan.

Define American. (n.d.). Define American: About. Retrieved from https://www. defineamerican.com/about

Gillig, T. K., Rosenthal, E. L., Murphy, S. T., \& Folb, K. L. (2018). More than a media moment: The influence of televised storylines on viewers' attitudes toward transgender people and policies. Sex Roles, 78, 515-527. https://doi. org/10.1007/s11199-017-0816-1

Green, M. (2021). Transportation into narrative worlds. In L. Frank \& P. Falzone (Eds.), Entertainment-education behind the scenes: Case studies for theory and practice. Palgrave Macmillan.

Hether, H. J., Huang, G., Beck, V., Murphy, S. T., \& Valente, T. W. (2008). Entertainment-education in a media-saturated environment: Examining the impact of single and multiple exposures to breast cancer storylines on two popular medical dramas. Journal of Health Communication, 13(8), 808-823. https://doi.org/10.1080/10810730802487471

Jauriqui, V. (2020). Understanding poverty in mass media: Opinions and insights. A report to the Bill \& Melinda Gates Foundation. USC Annenberg Norman Lear Center.

Karlin, B., Chapman, D., \& Saucier, C. (2018). Pressing for change: The role of action buttons in online news engagement. USC Annenberg Norman Lear Center. Retrieved from http://www.mediaimpactproject.org/uploads/ $5 / 1 / 2 / 7 / 5127770 /$ pressing_for_change.pdf

Karlin, B., Kim, H. T., Kelly, R., Blakley, J., Brenner, C., \& Riley, P. (2018). Does medium matter? Exploring the role of virtual reality in journalism. USC Annenberg Norman Lear Center. Retrieved from http://www.mediaimpactproject.org/uploads $/ 5 / 1 / 2 / 7 / 5127770 /$ frontlinevrreport_final.pdf

Kennedy, M. G., O’Leary, A., Beck, V., Pollard, W. E., \& Simpson, P. (2004). Increases in calls to the CDC National STD and AIDS hotline following AIDSrelated episodes in a soap opera. Journal of Communication, 54(2), 287-301. https://doi.org/10.1111/j.1460-2466.2004.tb02629.x

Kim, G., \& Rosenthal, E. L. (2020, October). "Nightwatch": Effects of a Nuclear Risk Storyline on the Popular Show Madam Secretary on Viewers' Knowledge, Attitudes, and Behaviors [Conference workshop]. National Conference on Health Communication, Marketing, and Media, Atlanta, GA. https://nphic. confex.com/nphic/2020/meetingapp.cgi/Paper/2170

Moyer-Gusé, E. (2008). Toward a theory of entertainment persuasion: Explaining the persuasive effects of entertainment-education messages. Communication Theory, 18(3),407-425.https://doi.org/10.1111/j.1468-2885.2008.00328.x Murphy, S. T., Frank, L. B., Moran, M. B., \& Patnoe-Woodley, P. (2011). Involved, transported, or emotional? Exploring the determinants of change in knowledge, attitudes, and behavior in entertainment-education. Journal 
of Communication, 61(3), 407-431. https://doi.org/10.1111/ j.1460-2466.2011.01554.x

Murphy, S. T., Wilkin, H. A., Cody, M. J., \& Huang, G. C. (2008). Health messages on primetime television: A longitudinal content analysis. In A. Jordan, D. Kunkel, J. Manganello, \& M. Fishbein (Eds.), Media messages and public health: A decisions approach to content analysis (pp. 173-191). Routledge.

The Opportunity Agenda. (2017). Power of POP: Media analysis of immigrant representation in popular TV shows. The Opportunity Agenda. Retrieved from https://www.opportunityagenda.org/sites/default/files/2017-06/ PopCultureReport-FINAL_06.14.pdf

Parker, K., Horowitz, J. M., \& Anderson, M. (2020, June 12). Amid protests, majorities across racial and ethnic groups express support for the Black Lives Matter movement. Pew Research Center: Social \& Demographic Trends. Retrieved from https://www.pewsocialtrends.org/2020/06/12/amidprotests-majorities-across-racial-and-ethnic-groups-express-support-for-theblack-lives-matter-movement/

Rosenthal, E. L., Buffington, S. C., \& Cole, G. (2018). From the small screen to breast cancer screening: Examining the effects of a television storyline on awareness of genetic risk factors. Journal of Communication in Healthcare, 11(2), 140-150. https://doi.org/10.1080/17538068.2018.1438766

Rosenthal, E.L., \& Gillig, T. (2017, August 8). Can transgender TV characters help bridge an ideological divide? The Conversation. Retrieved from https:// theconversation.com/can-transgender-tv-characters-help-bridgean-ideological-divide-81914

Rosenthal, E., Rogers, A., Peterson, E., Watson-Currie, E., \& Shin, H. (2020). Change the narrative, change the world: How immigrant representation on television moves audiences to action. A report to Define American. USC Annenberg Norman Lear Center. Retrieved from https://download.defineamerican.com $/ 2020 / 09 /$ Change-the-Narrative-Change-the-World.pdf

Singhal, A., Cody, M., Rogers, E., \& Sabido, M. (2004). Entertainment-education and social change: History, research, and practice. Erlbaum.

Singhal, A., \& Rogers, E. M. (2002). A theoretical agenda for entertainmenteducation. Communication Theory, 12(2), 117-135. https://doi. org/10.1111/j.1468-2885.2002.tb00262.x

Slater, M. D., \& Rouner, D. (2002). Entertainment-education and elaboration likelihood: Understanding the processing of narrative persuasion. Communication Theory, 12(2), 173-191. https://doi.org/10.1111/ j.1468-2885.2002.tb00265.x

Steinmetz, K. (2014, May 29). The transgender tipping point. Time. Retrieved from http://time.com/135480/transgender-tipping-point/ 
Walter, N., Murphy, S. T., \& Rosenthal, E. L. (2018). Narrative persuasion in a new media environment: The impact of binge watching and second-screening. Communication Research Reports, 35(5), 402-412. https://doi.org/10.108 0/08824096.2018.1525348

Wikipedia. (n.d.-a). Madam Secretary (season 4). Retrieved from https://en.wikipedia.org/wiki/Madam_Secretary_(season_4)

Wikipedia. (n.d.-b). Madam Secretary (season 5). Retrieved from https://en.wikipedia.org/wiki/Madam_Secretary_(season_5)

Open Access This chapter is licensed under the terms of the Creative Commons Attribution-NonCommercial-NoDerivatives 4.0 International License (http:// creativecommons.org/licenses/by-nc-nd/4.0/), which permits any noncommercial use, sharing, distribution and reproduction in any medium or format, as long as you give appropriate credit to the original author(s) and the source, provide a link to the Creative Commons licence and indicate if you modified the licensed material. You do not have permission under this licence to share adapted material derived from this chapter or parts of it.

The images or other third party material in this chapter are included in the chapter's Creative Commons licence, unless indicated otherwise in a credit line to the material. If material is not included in the chapter's Creative Commons licence and your intended use is not permitted by statutory regulation or exceeds the permitted use, you will need to obtain permission directly from the copyright holder. 